G. R. Dohle ·J. A. M. Beekhuis - G.-J. van Steenbrugge

F.H. Schröder $\cdot$ H. J. Tanke

\title{
Nuclear protein as a prognostic factor of growth activity in prostatic adenocarcinoma
}

Received: 15 May 1995 / Accepted: 10 January 1996

\begin{abstract}
The value of nuclear protein (NP) as a prognostic parameter in prostatic adenocarcinoma was investigated. The NP and DNA contents of two prostatic tumour lines with a well-documented hormonal dependency (PC-82, PC-EW) were compared to the NP and DNA contents of two xenografts with only partial or no response to androgen deprivation $(\mathrm{LNCaP}, \mathrm{PC}-$ 133). After hormonal treatment the PC- 82 and PC-EW tumours showed a significant decrease in the NP/DNA ratio, which coincided with a decrease in the proliferative activity [anti-bromodeoxyuridine (BRDU) antibody-labelling index] of the same specimens. In the fast-growing LNCaP tumour an increased percentage of cells with high NP and DNA contents was found. The tumours PC-82, PC-EW, and PC-133 with lower proliferative activity showed lower nuclear protein and DNA contents. In a pilot study of 20 prostatic biopsies the amount of nuclear protein and DNA in grade 1-3 tumours as well as in dysplasia was measured. Statistically significant differences $(P<0.002)$ were found between grade 1 and grade 3 tumours. The mean NP/DNA ratio was increased in high-grade malignancies. Nuclear protein appeared to be a potential parameter in predicting growth activity in prostatic carcinoma.
\end{abstract}

Key words Nuclear protein $\cdot \mathrm{DNA} \cdot$ Prostatic adenocarcinoma $\cdot$ Cell proliferation

G. R. Dohle (可) G.-J van Steenbrugge F. H. Schröder Department of Urology, University Hospital Rotterdam, Dr. Molewaterplein 40, 3015 GD Rotterdam, The Netherlands

G. R. Dohle J. A. M. Beekhuis · H. J. Tanke

Department of Cytochemistry and Cytometry, State University Leiden, Leiden, The Netherlands

\section{Introduction}

Prostatic adenocarcinoma is a common disease in elderly men. The number of prostatic tumours is increasing in incidence, due to the rising number of aged men and improvements in diagnostic ability to detect this malignancy at an early stage. The prevalence of prostatic carcinoma at autopsy is $30 \%$ in the 7 th decade of life. Only one-third of these prostatic cancers become clinically manifest and one in three patients die of the disease. The natural history of prostatic carcinoma is still unpredictable: much depends on tumour stage and tumour grade. The aggressiveness of the tumour is determined by several factors, including growth activation and genetic instability [19].

Disease progression and metastases occur in most patients with advanced stage and grade. In metastatic disease endocrine therapy prolongs the time to progression. In cases of relapse after adequate endocrine therapy, approximately $90 \%$ of patients die from their disease within 2 years $[3,18]$.

In advanced tumours various degrees of differentiation are found: well-differentiated tumour cells are found next to anaplastic tumour areas. Undifferentiated tumour cells have lost their potency to respond to androgen deprivation and their growth activity is responsible for progression towards androgen-independent disease [9].

Several tumour markers have been investigated to provide better information about tumour behaviour. Both the monoclonal antibodies Ki-67 and anti-bromodeoxyuridine (anti-BRDU) were found to be suitable cell proliferation markers, being expressed only in cycling and S-phase cells, respectively $[12,13]$. In addition, nuclear morphometry, DNA ploidy, and image cytometry have provided important information about tumour behaviour $[4,21]$. Using quantitative cell analysis, Auer et al. [1] determined the proliferative activity of lymphocytes by measuring the amount of nuclear 
protein (NP). Compared to non-cycling cells, a two- to threefold increase in total nuclear protein content was found in the G1 phase of the cell cycle, which was considered an early sign of growth activation.

In this pilot study we investigated whether nuclear protein is a suitable parameter for predicting growth activation in human prostatic carcinoma.

\section{Materials and methods}

\section{Tumour models}

Four prostatic tumour lines which are permanently transplantable in athymic nude mice were used. Table 1 shows estimated tumour doubling time in vivo in nude mice and the response to hormonal deprivation of the PC-82, PC-EW, PC-133, and LNCaP xenografts. The PC-82 tumour line, derived from a moderately differentiated human prostatic carcinoma, has high-affinity specific androgen receptors and responds to androgen deprivation by growth arrest [6]. The PC-EW tumour, which is derived from a lymph node metastasis of human prostate cancer, consists of moderately and poorly differentiated tumour tissue. The tumour contains androgen receptors and also responds to androgen deprivation [7]. The $\mathrm{LNCaP}$ tumour line, which is aneuploid, was derived from a lymph node metastasis of a human prostatic carcinoma. Cultured LNCaP cells were injected into athymic mice and subsequently solid tumours developed, of which the tissue was serially transplantable [22]. The rate of tumour growth of the $\mathrm{LNCaP}$ tumour is independent of the hormonal status of the host animal $[2,8]$. The PC-82 and PC-EW tumours have a low growth activity compared to the LNCaP tumour. The PC-133 tumour is derived from a poorly differentiated human prostatic carcinoma, it does not contain androgen receptors and it shows androgen-independent growth.

The number of proliferating cells in the PC-82 and the PC-EW tumours was estimated before and after hormonal treatment using the anti-BRDU antibody-labelling technique. With respect to nuclear protein as prognostic marker, the hormone-dependent tumour models (PC-82, PC EW) were compared to the tumour cell lines with only partial response (LNCaP) or no response to androgen deprivation (PC-133).

\section{Patient material}

As a pilot study, 20 specimens of human prostatic epithelium were investigated with no prior knowledge of the bistological diagnosis (WHO grading [11]) of the tumour. The NP/DNA ratio of $50-100$ cells per specimen was measured by cytophotometry. Prostatic carcinoma cells were obtained for cyto-analysis using the transrectal aspiration biopsies technique as described by Franzèn et al. [5].

Table 1 Characteristics of four human prostatic tumour lines, permanently transplantable in athymic mice

\begin{tabular}{llll}
\hline Tumour & Grade & $\begin{array}{l}\text { Doubling time } \\
\text { (days) }\end{array}$ & $\begin{array}{l}\text { Androgen } \\
\text { dependency }\end{array}$ \\
\hline PC-82 & 2 & 18 & Dependent \\
PC-EW & $2 / 3$ & 10 & Dependent \\
PC-133 & 3 & 10 & Independent \\
LNCaP & 3 & 5 & Partly dependent \\
\hline
\end{tabular}

\section{Staining procedure}

The puncture needle was flushed several times in a preservation medium containing polyonic in $25 \%$ ethanol. The suspension was centrifuged $(10 \mathrm{~min} \times 25 \mathrm{~g})$ and the supernatant was resuspended in $1 \mathrm{ml}$ Carbowax, centrifuged again and diluted to a cell concentration of about 20000 cells $/ \mathrm{ml}$. Slide preparation was performed with a 2-ml suspension in buckets for centrifugation at high force $(15 \mathrm{~min} \times 1250 \mathrm{~g})$. The slides were air dried at room temperature and stained with acriflavine-Feulgen-SITS (AFS) for DNA and protein. Rainbow trout erythrocytes were used for DNA and NP reference.

The AFS-staining procedure uses acriflavine-Feulgen, which quantitatively stains DNA in the nucleus, and stilbene isothyonate sulphonic acid (SITS), which is semiquantitatively bound to cellular protein [23]. This staining procedure has been developed for automated cancer screening, but is also suitable for cytomorphological interpretation [20]. The nucleus and the cytoplasm can be sequentially visualized using the different spectral characteristics of the two dyes: acriffavine-Feulgen absorbs blue light with a wavelength of $466 \mathrm{~nm}$, resulting in a yellow nuclear fluorescent image with clear morphological detail, whereas SITS is invisible at this wavelength. The SITS image can be visualized using excitation with UV light, resulting in a blue fluorescent image of cellular protein.

The slides were fixed in $100 \%$ ethanol for $60 \mathrm{~min}$. After $3 \mathrm{~min}$ rinsing with distilled water, hydrolysis was performed in $\mathrm{HCl} 5 \mathrm{~N}$ at $28^{\circ} \mathrm{C}$ for $45 \mathrm{~min}$. Another $3 \mathrm{~min}$ rinsing was followed by staining with acriflavine $\left(0.1 \%\right.$ at $\left.28^{\circ} \mathrm{C}\right)$ for $30 \mathrm{~min}$. Non-covalently bound acriflavine was removed by a solution of $1 \% \mathrm{HCl}$ in $70 \%$ ethanol. Preparations were rinsed with phosphate-buffered solution (PBS) for $5 \mathrm{~min}$ and citric acid phosphate buffer $(\mathrm{pH}=5.5)$ for $5 \mathrm{~min}$. The protein was then stained by SITS in $0.01 \%$ citric acid phosphate buffer for $15 \mathrm{~min}$. Dehydration was performed in $100 \%$ ethanol for 30 min. The slides were mounted in Fluoromount (Sigma, St. Louis).

Nuclear protein and DNA measurements

Using the appropriate filters (LP 515, KP 490), the fluorescence signals were measured sequentially within the nucleus of the cell with an MPV microscope fluorometer (Leitz, Germany) [18]. The nuclear protein and DNA contents of approximately 100 nuclei per specimen were measured sequentially. The measurements of absolute fluorescence signals are hampered by several variable factors, including light scatter from the mercury lamp and photoblending of the label due to repeated light exposure. Since these factors affect both NP and DNA measurements equally, determination of the NP/DNA ratio permits comparison of the results of different slides.

The NP/DNA ratio was determined for each nucleus. The results of these measurements were compared with the results of the histological diagnosis of the same tumour, using the WHO classification for tumour grading [11].

\section{Statistics}

Statistical analysis was performed using Wilcoxon's rank sum test and Student's $t$-test, provided by the SPSS/PC computer program (SPSS, Chicago). Fifty to 100 items of data per specimen were available for statistical analysis. Differences were considered significant at $P<0.05$.

\section{Results}

The nuclear protein and DNA contents of 50-100 tumour cells per specimen of the four tumour lines were measured. Figure 1 shows the NP/DNA profile of the 
number of cells $(\%)$

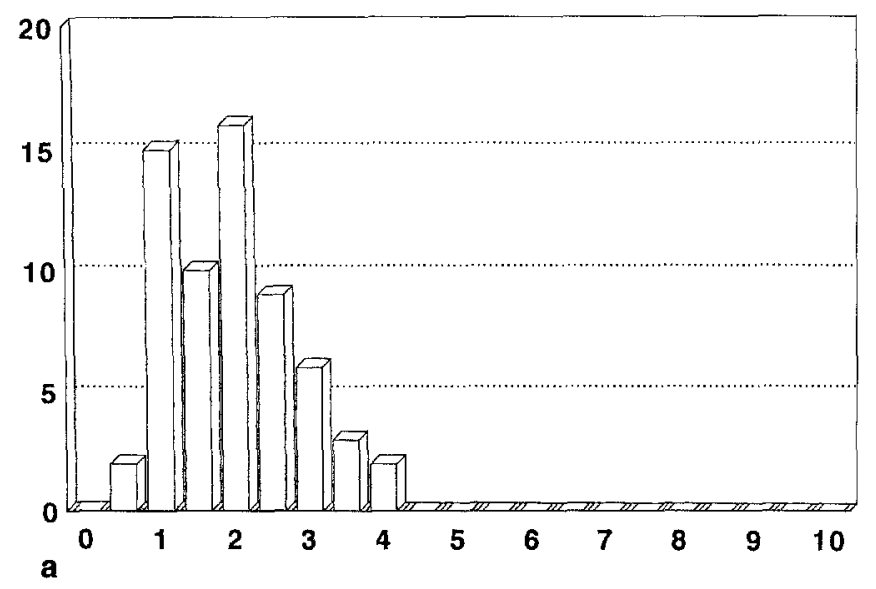

number of cells $(\%)$

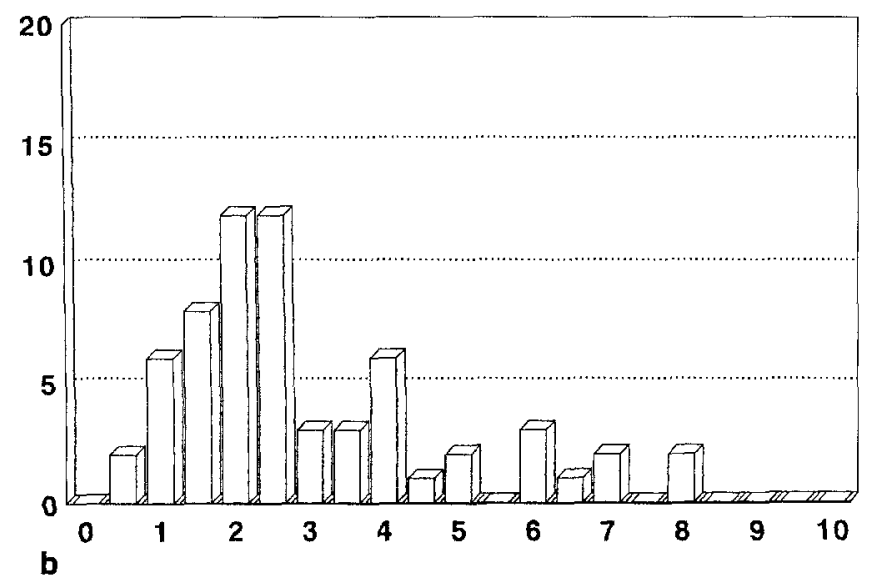

Fig. 1 Histograms of the mean NP/DNA ratio (and standard deviation) of $\mathbf{a} \mathrm{PC}-82$ and $\mathbf{b} \mathrm{LNCaP}$ tumour lines, growing in untreated male mice. a Mean ratio $=2.16 ; \mathrm{SD}=0.75$. b Mean ratio $=3.38$; $\mathrm{SD}=1.69$

PC-82 tumour and the LNCaP tumour. An increasing number of cells with high DNA and NP contents are observed in the LNCaP tumour.

The NP/DNA ratio and the percentage of cells with high NP and DNA contents of the PC-82 and PC-EW tumours were measured before and after androgen deprivation and compared to the anti-BRDU antibody-labelling index of the same tumours (Table 2). Castration of the nude male mice resulted in a significant decrease in the NP/DNA ratio in both tumours. Moreover, the number of cells with high NP and DNA contents decreased, comparable to the decrease in the anti-BRDU labelling index. The number of cells exceeding twice the NP and DNA reference values (rainbow trout erythrocytes) also decreased after androgen deprivation (Table 2). The coefficient of variation of the mean NP/DNA ratio of the rapidly growing $\mathrm{LNCaP}$ tumour was statistically different $(P<0.001)$ from the value of the relatively slow-growing $\mathrm{PC}-82, \mathrm{PC}-\mathrm{EW}$ and PC-133 tumours (Fig. 1).
Table 2 NP/DNA ratio and percentage of cells with nuclear protein and DNA contents exceeding twice the reference value (rainbow trout erythrocytes) of four tumour lines of human prostatic adenocarcinoma, before and after hormonal deprivation. The hormonaldependent tumour lines PC-82 and PC-EW were measured before and 30 days after castration of the athymic mouse and the antiBRDU index was determined from the same specimen (Anti-BRDU anti-bromodeoxyuridine labelling index, $N D$ not determined)

\begin{tabular}{llcc}
\hline & $\begin{array}{l}\text { NP/DNA } \\
\text { ratio }\end{array}$ & $\begin{array}{c}\% \text { cells exceeding } \\
2 \times \mathrm{NP} / 2 \times \mathrm{DNA}\end{array}$ & $\begin{array}{c}\text { Anti-BRDU } \\
\text { index }(\%)\end{array}$ \\
\hline PC-82 & & & \\
$\quad$ Before castration & 2.16 & 13.0 & 10.0 \\
$\quad$ After castration & 1.14 & 0 & 0.6 \\
PC-EW & & & \\
Before castration & 2.31 & 13.3 & 6.1 \\
$\quad$ After castration & 1.08 & 1.9 & 0.8 \\
PC-133 & 2.87 & 9.6 & $\mathrm{ND}$ \\
LNCaP & 3.38 & 10.4 & $\mathrm{ND}$ \\
\hline
\end{tabular}

The mean NP/DNA ratio of 20 specimens of human prostatic adenocarcinoma was compared to the histological grade of the same tumour (Table 3). Although statistically not significant, a tendency towards a higher mean NP/DNA ratio in high-grade malignant tumours was observed $(P>0.05)$. Dysplasia, characterized by an increased mitotic activity, also showed a high NP/DNA ratio, due to an increasing number of cells with a high nuclear protein content. Figure $2 a-c$ shows examples of scatterplots of grade 1-3 malignant specimens. A statistically significant difference was found between the grade 1 and grade 3 tumours $(P<0.002$, Table 3$)$.

\section{Discussion}

Nuclear protein has been investigated as a parameter of cell proliferation in human prostatic carcinoma. Changes in nuclear protein and DNA content in the different stages of the cell cycle have been described by Roti Roti et al. [17] and Pollack et al. [16]. Nuclear protein content changed from low values during the G0 phase to high values in the early G1 phase. A two- to threefold increase in protein was followed by a duplication of DNA in the S-phase. The nuclear protein/DNA ratio remained high during all phases of the cell cycle (Fig. 3). The number of proliferating cells could be determined by measuring their nuclear protein content $[1,17]$. Using the R3327-G rat prostatic carcinoma, Pollack et al. [16] showed that the number of cells in the mid-S phase was increased after treatment with testosterone. Changes in the nuclear protein content appeared to proceed a change in tumour volume. The aim of the present study was to investigate NP as a potential prognostic factor in prostatic carcinoma. From the work of Pollack et al. [16], it was concluded that NP 


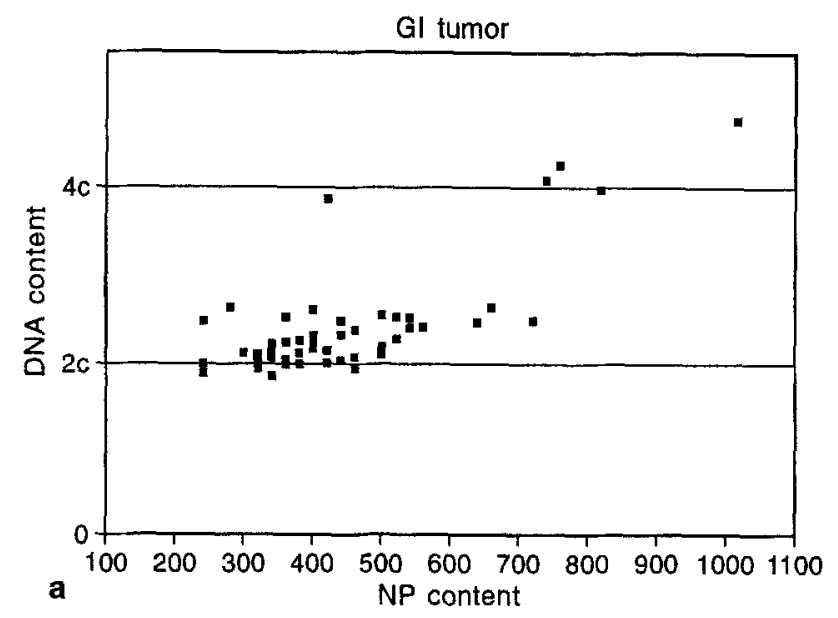

Table 3 A pilot study of 20 cytological smears of human prostatic adenocarcinoma, comparing the mean NP/DNA ratio (range, SD) to the histological diagnosis (WHO grading) of the same tumours (No. number of specimens, Ratio mean NP/DNA ratio, SD standard deviation)

\begin{tabular}{rrlll}
\hline No. & Ratio & Range & SD & Histology \\
\hline 1 & 3.89 & $0.9-5.4$ & 1.17 & Gr 1 \\
2 & 4.76 & $1.3-8.7$ & 1.89 & Gr 1 \\
3 & 2.97 & $0.5-6.7$ & 1.54 & GR 2 \\
4 & 2.00 & $1.0-5.1$ & 0.82 & GR 2 \\
5 & 3.74 & $0.5-7.8$ & 1.92 & GR 2 \\
6 & 5.27 & $1.1-10.4$ & 2.35 & GR 2 \\
7 & 7.45 & $4.1-14.4$ & 2.78 & GR 2 \\
8 & 5.46 & $0.6-11.1$ & 2.84 & GR 2-3 \\
9 & 6.04 & $1.3-15.4$ & 3.48 & GR 2-3 \\
10 & 7.93 & $1.5-16.7$ & 4.18 & GR 2-3 \\
11 & 5.10 & $0.1-10.6$ & 2.42 & GR 3 \\
12 & 6.05 & $1.0-11.4$ & 2.92 & GR 3 \\
13 & 7.26 & $1.1-11.9$ & 2.44 & GR 3 \\
14 & 10.52 & $3.1-17.1$ & 3.10 & GR 3 \\
15 & 5.05 & $1.0-9.0$ & 1.80 & Dysplasia \\
16 & 6.59 & $0.1-17.9$ & 4.12 & Dysplasia \\
17 & 8.72 & $4.1-16.7$ & 3.42 & Dysplasia \\
18 & 8.77 & $3.1-14.7$ & 3.01 & Dysplasia \\
19 & 8.79 & $1.6-18.7$ & 4.43 & Dysplasia \\
20 & 9.80 & $1.3-17.1$ & 5.08 & Dysplasia \\
\hline
\end{tabular}

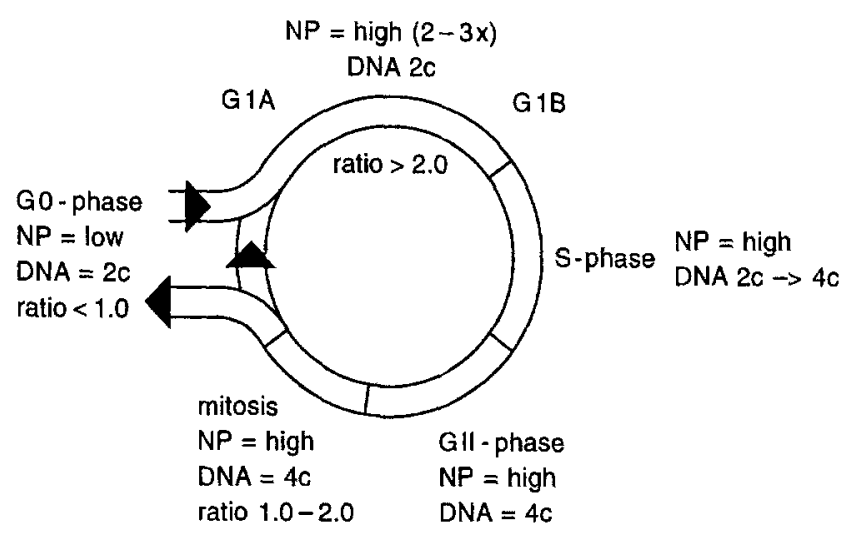

Fig. 3 Cell cycle position, nuclear protein content and DNA content

ation and is not cancer specific. A comparison was made to other cell proliferation markers, showing a remarkable similarity.

Two tumour lines (PC-82, PC-EW) with a relatively

Fig. 2 a Example of a scatterplot (NP content versus DNA content) of a grade 1 human prostatic adenocarcinoma. Most tumour cells have NP and DNA contents comparable to non-cycling cells. b Example of a grade 2 tumour. Number of cells with high NP and DNA contents is increasing. $\mathrm{c}$ Example of a grade 3 tumour. A dissociation between NP and DNA is observed

was associated with androgen dependency. Therefore, we selected xenograft models with a different response to androgen deprivation. From our early results, however, it was concluded that NP is related to cell proliferslow growth rate and with well-documented hormonal dependency were compared to two tumour lines (LNCaP, PC-133) with only partial or no response to androgen deprivation in the athymic mouse. The fastgrowing LNCaP tumour appeared to have a high mean NP content, indicating that nuclear protein content increases in proliferating tumours. Androgen deprivation of the PC-82 and PC-EW tumours resulted in growth arrest and in a significant decrease in the number of proliferating cells (Table 2). This was associated 
with a significant decrease in the percentage of cells exceeding a twofold elevation of the reference NP and DNA contents.

In a pilot study of biopsy material the amount of nuclear protein in grade 1-3 tumours as well as in dysplasia was measured. In spite of the limited number of tumours studied, a statistically significant difference was found between the grade 1 and grade 3 tumours. Dysplastic tissue, characterized by a high number of proliferating cells, also showed high NP contents. The mean value of the NP/DNA ratio was increased in dedifferentiated tumours, which could be separated from the grade 1-2 tumours by estimating the NP/DNA ratio.

To our knowledge there is no other study which has measured the same parameters in prostatic carcinoma. In two studies of human endometrium, Oud et al. $[14,15]$ showed that by measuring the NP/DNA ratio of isolated nuclei benign and malignant cells could be separated. Morberger et al. [10] showed that normal NP and DNA characteristics were found in euploid endometrial tumours. Aneuploid tumours, in contrast, showed DNA and NP values indicative of increased proliferation activity as well as for a pronounced disorder between DNA and NP.

The outcome of the present study suggests that nuclear protein is a possible parameter in predicting proliferative activation in prostatic carcinoma. Since NP increases in the very early phase of the cell cycle, it might have additional advantages over other proliferation markers. Furthermore, it has been developed as a simple technique, suitable for cytophotometry, automated image analysis and flow cytometry. The potency of this parameter is currently being investigated in a prospective study.

\section{References}

1. Auer G, Ono J, Caspersson TO (1983) Determination of the fraction of $\mathrm{G} 0$ cells in cytological samples by means of simultaneous DNA and nuclear protein analyses. Anal Quant Cytol 5:1

2. Berns EMJJ, de Boer W, Mulder E (1986) Androgen-dependent growth regulation of and release of specific protein(s) by the androgen receptor containing human prostate tumour cell line LNCaP. Prostate 9:247

3. Byar DP, Corle D (1988) Hormone therapy for prostate cancer: results of the Veterans Administration Cooperative Urological Research Group studies. In: Consensus Development Conference in the Management of Clinically Localized Prostate Cancer, Bethesda. NCI Monogr 7:165

4. Diamond DA, Berry SJ, Jewett HJ, Eggleston JC, Coffey DS (1982) A new method to assess metastatic potential of human prostate cancer: relative nuclear roundness. J Urol 128: 792
5. Franzèn S, Giertz G, Zajicek J (1960) Cytological diagnosis of prostatic tumours by transrectal aspiration biopsy; a preliminary report. Br J Urol 32:193

6. Hoehn W, Schroeder FH, Riemann JF, Joebsis AC, Hermanek P (1980) Human prostatic adenocarcinoma: some characteristics of a serially transplantable line in nude mice (PC 82). Prostate 1:95

7. Hoehn W, Wagner M, Riemann JF, Hermanek P, Williams E, Walther R, Schrueffer R (1984) Prostatic adenocarcinoma PC$\mathrm{EW}$, a new human tumor line transplantable in nude mice. Prostate 5:445

8. Horoszewicz JS, Leong SS, Kawinski E, Karr JP, Rosenthal H, Ming Chu T, Mirand EA, Murphy GP (1983) LNCaP model of human prostatic carcinoma. Cancer Res 43:1809

9. Isaacs JT, Heston WDW, Weissman RM, Coffey DS (1978) Animal models of the hormone sensitive and insensitive prostatic adenocarcinoma, Dunning R-3327-H, R-3327-HI, and R3327-AT. Cancer Res 38:4353

10. Morberger B, Sennerstam R, Auer G (1989) DNA and nuclear protein characteristics in non-neoplastic and neoplastic endometrial tissue. Anal Cell Pathol 2:15

11. Mostofi FK (1975) Grading of prostatic carcinoma. Cancer Chemother Res 59:111

12. Nemoto R, Uchida K, Shimazui T, Hattori K, Koiso K, Harada M (1989) Immunocytochemical demonstration of S-phase cells by anti-bromodeoxyuridine monoclonal antibody in human prostate adenocarcinoma. J Urol 141:337

13. Oomens EHGM, Van Steenbrugge GJ, Van Der Kwast ThT, Schröder FH (1991) Application of the monoclonal antibody $\mathrm{Ki}-67$ on prostate biopsies to assess the proliferative cell fraction of human prostatic carcinoma. J Urol 145:81

14. Oud PS, Reubsaet-Veldhuizen JAM, Henderik JBJ, Pahlplatz MMM, Hermkens HG, Tas J, James J, Peter Vooijs G (1986) DNA and nuclear protein measurement in isolated nuclei of human endometrium. Cytometry 7:318

15. Oud PS, Reubsaet-Veldhuizen JAM, Beck LM, Pahlplatz MMM, Hesslmans GHFM, Hermkens $H_{G}$, Tas J, James J, Peter Vooijs G (1986) DNA and nuclear protein measurement in columnar epithelial cells of human endometrium. Cytometry $7: 325$

16. Pollack A, Moulis H, Block NL, Irvin GL (1984) Quantitation of cell kinetic responses using simultaneous flow cytometric measurements of DNA and nuclear protein. Cytometry 5:473

17. Roti Roti JL, Higashikubo R, Blair OC, Uygur N (1982) Cellcycle position and nuclear protein content. Cytometry 3:91

18. Slack NH, Mittelman A, Brady MF, Murphy GP (1980) The importance of the stable category for chemotherapy treatment patients with advanced and relapsing prostate cancer. Cancer 46:2393

19. Stamey TA, McNeal JE (1992) Adenocarcinoma of the prostate In: Walsh PC, Retik AB, Stamey TA, Vaughan E (eds) Campbells urology, vol 2. Saunders, Philadelphia, p 1159

20. Tanke HJ, van Ingen EM, Ploem SJ (1979) Acriflavine-Feulgenstilbene staining: a procedure for automated cervical cytology with a television based system (LEYTAS). J Histochem Cytochem 27:84

21. Tribukait B (1987) Flow cytometry in assessing the clinical aggressiveness of genito-urinary neoplasms. World J Urol 5:108

22. Van Steenbrugge GJ, Zhao X, Van Uffelen CJ, Mulder E, Schröder FH (1992) Permanent propagation of the human prostatic carcinoma cell line LNCaP in athymic nude mice. Urol Res 20:436

23. Wollmer W (1981) Scanning microflurometric measurements of acriflavine-Feulgen-SITS stained fibroblasts during G0-G1 transition. Anal Quant Cytol 3:305 